\title{
Biomonitoring of urinary metals in athletes according to particulate matter air pollution before and after exercise
}

\author{
Sabina Cauci ${ }^{1}$ (1) $\cdot$ Michael Tavano $^{1} \cdot$ Francesco Curcio $^{1,2} \cdot$ Maria Pia Francescato ${ }^{1}$
}

Received: 2 August 2021 / Accepted: 20 November 2021 / Published online: 2 December 2021

(c) The Author(s), under exclusive licence to Springer-Verlag GmbH Germany, part of Springer Nature 2021

\begin{abstract}
Exposure to air pollution during physical exercise is a health issue because fine particulate matter (dimension $<10 \mu \mathrm{m} ; \mathrm{PM}_{10}$ ) includes several inhalable toxic metals. Body metal changes in athletes according to air pollution are poorly known. Urinary concentrations of 15 metals: beryllium $\left(\mathrm{Be}^{9}\right)$, aluminum $\left(\mathrm{Al}^{27}\right)$, vanadium $\left(\mathrm{V}^{51}\right)$, chromium $\left(\mathrm{Cr}^{51}+\mathrm{Cr}^{52}\right)$, manganese $\left(\mathrm{Mn}^{55}\right)$, cobalt $\left(\mathrm{Co}^{59}\right)$, nickel $\left(\mathrm{Ni}^{61}\right)$, copper $\left(\mathrm{Cu}^{63}\right)$, zinc $\left(\mathrm{Zn}^{61}\right)$, arsenic $\left(\mathrm{As}^{75}\right)$, selenium $\left(\mathrm{Se}^{82}\right)$, cadmium $\left(\mathrm{Cd}^{111}+\mathrm{Cd}^{112}\right)$, thallium $\left(\mathrm{Tl}^{125}\right)$, lead $\left(\mathrm{Pb}^{207}\right)$, and uranium $\left(\mathrm{U}^{238}\right)$ were measured before and after ten 2-h training sessions in 8 non-professional Italian American-football players (18-28 years old, body mass index $\left.24.2-33.6 \mathrm{~kg} / \mathrm{m}^{2}\right)$. Collectively, post-training sessions, urinary concentrations of $\mathrm{As}, \mathrm{Cd}, \mathrm{Co}, \mathrm{Cu}, \mathrm{Mn}, \mathrm{Ni}, \mathrm{Pb}, \mathrm{Se}, \mathrm{Tl}$, and $\mathrm{Zn}$ were higher than pre-training sessions; $\mathrm{Al}, \mathrm{Be}, \mathrm{Cr}$, and $\mathrm{U}$ did not change; conversely, $\mathrm{V}$ decreased. Subdividing training sessions according to air $\mathrm{PM}_{10}$ levels: low $\left(<20 \mu \mathrm{g} / \mathrm{m}^{3}\right)$, medium $\left(20-40 \mu \mathrm{g} / \mathrm{m}^{3}\right)$, and high $\left(>40 \mu \mathrm{g} / \mathrm{m}^{3}\right)$, pre-session and post-session urinary concentrations of $\mathrm{Be}, \mathrm{Cd}, \mathrm{Cu}$, and $\mathrm{Tl}$ were significantly higher $(p<0.05)$ in more polluted days, whereas $\mathrm{V}$ concentrations were lower $(p<0.001)$. All the remaining metals were unaffected. We first showed that $\mathrm{PM}_{10}$ levels modulate urinary excretion of some toxic metals suggesting an effect of air pollution. The effects of toxic metals inhaled by athletes exercising in polluted air need further studies.
\end{abstract}

Keywords Urinary metals $\cdot$ Heavy metals $\cdot$ Air pollution $\cdot$ Particulate matter $\cdot$ Physical exercise $\cdot$ Athletes $\cdot$ American football

\section{Introduction}

Air pollution is complex to study because pollutants like particulate matter, ozone, nitric oxides $\left(\mathrm{NO}_{x}\right)$, black carbon, volatile organic compounds vary in amount and ratio according to the season, the emitting source of pollution,

Keypoints Exposure to air pollution during physical exercise is a health issue. Urinary concentrations of 15 metals were measured before/after training in 8 athletes. For most metals, post-training urinary concentrations were higher than pre-training. Moreover, urinary excretion of some toxic metals was modulated by air pollution (according to $\mathrm{PM}_{10}$ levels).

Responsible Editor: Lotfi Aleya

Sabina Cauci

sabina.cauci@uniud.it

1 Department of Medicine, School of Medicine, University of Udine, Piazzale Kolbe 4, 33100 Udine, Italy

2 Clinical Analysis Laboratory, Department of Laboratory Medicine, Institute of Clinical Pathology, Santa Maria della Misericordia University-Hospital, 33100 Udine, Italy the atmospheric conditions of the specific day, and also the hour within the same day (Bigazzi and Figliozzi 2014; de Nazelle et al. 2017; Newby et al. 2015; Perrino et al. 2020).

Notably, air pollution has been associated with increased risk of cardio/cerebrovascular diseases (CVDs) (Chowdhury et al. 2018; Nawrot et al. 2011), as well as with respiratory diseases (Koh et al. 2019; Mayer and Hamzeh 2015), increase of oxidative stress (Buha et al. 2021), systemic inflammation, endothelial dysfunction, atherothrombosis, and arrhythmogenesis (Chowdhury et al. 2018; Forastiere and Agabiti 2013; Mills et al. 2009; Newby et al. 2015), type 2 diabetes, some cancers, and premature mortality in the long term (Brook et al. 2017; Newby et al. 2015; Tainio et al. 2021). In athletes, the respiratory symptoms (e.g., decreased lung function resulting in decreased peak expiratory flow and increased airway inflammation; Qin et al. 2019), elevated blood pressure, and other cardiovascular conditions triggered by air pollution can even provoke impaired exercise capacity and reduced sport performance (An et al. 2019; An and Yu 2018; Nawrot et al. 2011; Tainio et al. 2021; WHO 2021 ). 
Interestingly, a recent review reported experts' consensus vision following an International collaboration call promoted by the World Health Organization that explored the shortterm and long-term health effects of air pollution exposure on people engaged in physical activity (Tainio et al. 2021). It is recognized that physical activity and air pollution are linked by multiple mechanisms and that high air pollution may even prevent people from engaging in physical activity overall (Qin et al. 2019; Smith et al. 2019; Tainio et al. 2021). Of concern is the impact of exposure to air pollution on outdoor exercises like cycling, walking, running, etc. Also, the so-called active transport performed by citizens could have health impacts because of the increased inhaled dose of air pollution due to increased ventilation while being engaged in physical activity (Bigazzi and Figliozzi 2014; Dons et al. 2017; Qin et al. 2019; Tainio et al. 2021).

Moreover, exposure to air pollution has been associated with semen quality and reduced fertility in young men (Bergamo et al. 2016). Specifically, subjects practicing physical activity in proximity of industrial and/or traffic polluted areas, where air pollution included higher $\mathrm{Cr}, \mathrm{Cu}$, and $\mathrm{Zn}$ were at increased risk of semen alterations (Bergamo et al. 2016; Montano et al. 2021).

Elevated levels of particulate matter (PM) specific exposure during exercise may contribute to changes in blood pressure, systemic conduit artery function, and microvascular function (An and Yu 2018; Qin et al. 2019). Particulate matter of $10 \mu \mathrm{m}$ or less in aerodynamic diameter $\left(\mathrm{PM}_{10}\right)$ and particulate matter of $2.5 \mu \mathrm{m}$ or less $\left(\mathrm{PM}_{2.5}\right.$ ) (which is a fraction included in $\mathrm{PM}_{10}$ roughly 50-80\%) are used as the main indicators of air pollution. Particulate matter composition is highly variable according to specific primary and secondary polluting molecules present in the inhalable air, which, in general, are geo-referred (Moon et al. 2021; Perrino et al. 2020). It is to highlight that PM constituents include trace metals, which often are heavy metals (Perrino et al. 2020). Particularly, arsenic (As), cadmium (Cd), nickel (Ni), and lead $(\mathrm{Pb})$ found in $\mathrm{PM}_{10}$ are subjected to quantitative limitations by the Italian and European legislation (Gonzalez Ortiz and De Brito Beirao Guerreiro 2020; Mistaro et al. 2018).

Several studies demonstrated that environmental chronic metals exposure in non-occupationally exposed general population is associated with several pathologic conditions including an increased risk of all-cause, cancer, and cardiovascular disease mortality (Chowdhury et al. 2018; Men et al. 2020; Menke et al. 2009; Newby et al. 2015). Environmental exposure to metals can have even neurotoxic effects; notably, $\mathrm{Cr}, \mathrm{Mn}$, and $\mathrm{Pb}$ were associated with lower Intellectual Quotient scores (Bauer et al. 2020; Lucchini et al. 2019).

Accumulating evidence points to urinary toxic metals as biomarkers of health risk. Indeed, biomonitoring of metals exposure is non-invasively performed by determination of their concentration in urine (Muñoz et al. 2019; Renzetti et al. 2021; Zeng et al. 2021). Elevated urinary levels of 3 heavy metals (total arsenic, lead, cadmium) were associated with higher total, malignant neoplasms and nephritis-related, mortality as well as higher gamma-glutamyl transferase (Yao et al. 2021). Moreover, urinary arsenic showed an impact on anxiety and depression, somatic problems, attention problems, and rule-breaking behavior (Renzetti et al. 2021).

Nevertheless, few studies examined metals in the urine of athletes.

A Spanish study (Llerena et al. 2012) measured 5 urinary metals: beryllium $(\mathrm{Be})$, cadmium $(\mathrm{Cd})$, lead $(\mathrm{Pb})$, tungsten $(\mathrm{W})$, and tellurium (Te), in athletes compared to sedentary controls, finding that $\mathrm{Be}, \mathrm{Cd}$, and $\mathrm{Te}$ were higher; conversely, $\mathrm{Pb}$ was lower in athletes, and $\mathrm{W}$ was not detectable in sedentary subjects. A further Spanish study (Muñoz et al. 2020) assessed that first-morning urinary concentrations of $\mathrm{As}, \mathrm{Be}, \mathrm{Cd}$, and $\mathrm{Pb}$ in long-distance athletes were unchanged after 6 months of aerobic training.

Very few studies examined metal urine changes after exercise. Anderson et al. (1984) examined Cu, Cr, and Zn; Granell (Granell 2014) measured $\mathrm{Cu}$ and $\mathrm{Zn}$ after aerobic exercise. Urinary Zn, molybdenum (Mo), selenium (Se), Co, $\mathrm{Cu}$, and $\mathrm{Mn}$ were evaluated in Spanish studies (Maynar et al. 2018a, b; Muñoz et al. 2019).

A wider study by Bartolomé et al. (2016) examined 7 urinary metals: As, $\mathrm{Cu}$, lithium $(\mathrm{Li}), \mathrm{Mo}, \mathrm{Ni}, \mathrm{Se}$, and $\mathrm{Zn}$ before and after a paddle competition finding that some metals increased; the others did not change and, unexpectedly, one ( $\mathrm{Li})$ decreased significantly after the effort. The authors concluded that exercise had heterogenic effects on mineral excretion, requiring further studies.

So far, no study examined the effects of exposure to varying air pollution levels during exercise on urinary concentrations of metals in the same athletes. Our study investigated the association of 15 urinary metal concentrations with outdoor air pollution in 8 American football players before and after 10 different days of 2-h exercise sessions.

\section{Methods}

\section{Population}

The study was conducted on a group of 8 non-professional American football players belonging to a team competing at regional (in Friuli-Venezia Giulia Region located in the Nord-East of Italy) and inter-regional levels, who volunteered to participate in a 10 -week-long (from February to April) experimentation performed during their scheduled usual training sessions. The characteristics of the athletes ranged as follows: they were 18 to 29 years old, had a body mass from 80 to $132 \mathrm{~kg}$, and a stature between 180 and $201 \mathrm{~cm}$. All participants were Caucasian subjects and living 
and working (or studying) within a 30-km distance from the location of the training field in Udine city. None had extreme or restricted alimentary habits (like vegan, etc.) and participants were asked to have a normal usual diet without alimentary excesses (Anderson et al. 1995); none declared continuative use of drugs; none had chronic pathologies (like type I diabetes, etc.); none was sick at the time of urine sample collection. No use of mineral supplements was allowed during the study period. Subjects smoking more than 20 cigarettes per week were excluded because of the possible inhalation of metals through smoke (Afridi et al. 2010; Satarug and Moore 2004).

Written informed consent was obtained from each volunteer before enrolment and no compensation or incentive was paid for participation in the study. The Institutional Ethical Committee of the Department of Medicine (University of Udine) approved the study, which was conducted according to the rules of the Declaration of Helsinki (1975).

\section{Design and setting of the study}

Data were collected on ten training sessions with different levels of air pollution, hereafter defined as experimental sessions, distributed along the experimental period. Training sessions were carried out in a sports field (S. Osvaldo, Udine), nearby which a control unit of the Regional Agency for the Protection of the Environment (ARPA) is placed, in order to detect daily and hourly the values of $\mathrm{PM}_{10}, \mathrm{O}_{3}, \mathrm{NO}_{x}$ (including $\mathrm{NO}$ and $\mathrm{NO}_{2}$ ), as well as ambient temperature, pressure, and humidity. Ambient temperature ranged from 1.5 to $12.4{ }^{\circ} \mathrm{C}$, pressure from 1006 to $1021 \mathrm{hPa}$, and humidity from 54 to $90 \%$.

Each training session lasted about $2 \mathrm{~h}$ (from 8:00 PM to 10:00 PM) and consisted of 30 min of light warm-up, 15 min of agility drills, followed by 45-60 min of technical exercises, with the final 15-30 min of simulated American football match. Training sessions were performed from 2 to 14 days apart.

Athletes were allowed to drink water ad libitum from bottles filled and weighted at the start of the session and containing the same kind of water in all experimental sessions (Francescato et al. 2019). At the end of the sessions, the bottles were weighted and the volume of water drunk during the session was calculated considering a water density of $1.0 \mathrm{~g} / \mathrm{mL}$.

Body mass and stature of each athlete were measured as described (Francescato et al. 2019), BMI was calculated by body mass $(\mathrm{kg})$ divided for the square of stature $(\mathrm{m})$.

Athletes' body mass was repetitively measured at the start and at the end of each session. Information concerning the use of medications in the preceding $24 \mathrm{~h}$ was recorded. Before the start and at the end of the experimental sessions, each volunteer provided a urine sample in a $50-\mathrm{mL}$ sterile polyethylene container, which was frozen at $-40^{\circ} \mathrm{C}$ until the measurements were performed. Overall, a total of 118 samples were analyzed, of which 59 were before and 59 were after the exercise training sessions; some samples were not collected because the volunteers did not always attend the training sessions (e.g., due to injuries or illnesses).

\section{Assessment of metals in the urine samples}

The inductively coupled plasma mass spectrometry (ICPMS) method was used to assess the metals in the urine samples; this method is known for its ability to detect several metals in liquid samples at very low concentrations, allowing also to detect the concentration of different isotopes of the same element. The instrument ICP-MS 7700x (Agilent Technologies, Waldbronn, Germany) was used. Measurements were performed as described (Knoop et al. 2020). Urine samples ( $1 \mathrm{~mL}$ of each subject) were 5 -fold diluted with $1 \% \mathrm{HNO}_{3}$ immediately before measurement. In each experimental session appropriate external calibration of the instrument was carried out with the ICP-MS standard multi-element tuning solution provided by the Agilent Technologies manufacturer; to determine the calibration curve 5 increasing concentrations of the standard solution were used. An Indium plasma emission standard was used as the internal standard (Knoop et al. 2020; Wilschefski and Baxter 2019).

Concentrations of 15 different metals were determined on each urine sample; the following isotopes were determined: $\mathrm{Be}^{9}, \mathrm{Al}^{27}, \mathrm{~V}^{51}, \mathrm{Cr}^{51}, \mathrm{Cr}^{52}, \mathrm{Mn}^{55}, \mathrm{Co}^{59}, \mathrm{Ni}^{61}, \mathrm{Cu}^{63}, \mathrm{Zn}^{61}, \mathrm{As}^{75}$, $\mathrm{Se}^{82}, \mathrm{Cd}^{111}$ and $\mathrm{Cd}^{112}, \mathrm{Tl}^{125}, \mathrm{~Pb}^{207}$, and Uranium ${ }^{238}$. Hereafter, only the metal name will be indicated, $\mathrm{Cd}^{111}$ summed to $\mathrm{Cd}^{112}$ will be indicated as $\mathrm{Cd}$, and $\mathrm{Cr}^{51}$ summed to $\mathrm{Cr}^{52}$ will be indicated as $\mathrm{Cr}$.

Limits of detection of each metal were evaluated as 3 times the standard deviation of the blank sample. No experimental data was below such threshold.

\section{Assessment of $\mathrm{PM}_{10}$ in ambient air}

The control unit of ARPA allows for the measurement of the mass of the particulate matter thanks to the principle of attenuation of the $\beta$ rays emitted by a radioactive source (Mistaro et al. 2018). The unit provides an hourly value of $\mathrm{PM}_{10}$ in the ambient air, which represents the average value over that hour. All the acquired data are registered on the web page of the Regional Agency (http://www.arpaweb.fvg. it/qagis/ariastor.asp), which was accessed to download the appropriate values. For the present investigation, the average value between the hourly data recorded from 7:00 PM to 10:00 PM was considered to represent the $\mathrm{PM}_{10}$ value of that training session. WHO proposed an annual limit value of 20 $\mu \mathrm{g} / \mathrm{m}^{3}$ for air pollution (WHO 2021), whereas the European 
Environmental Agency indicated $40 \mu \mathrm{g} / \mathrm{m}^{3}$ (Gonzalez Ortiz and De Brito Beirao Guerreiro 2020). Consequently, data were examined as a whole and then subdivided according to $\mathrm{PM}_{10}$ levels: low $\left(\mathrm{PM}_{10}<20 \mu \mathrm{g} / \mathrm{m}^{3}\right)$, medium $\left(20<\mathrm{PM}_{10}\right.$ $\left.<40 \mu \mathrm{g} / \mathrm{m}^{3}\right)$ and high $\left(\mathrm{PM}_{10}>40 \mu \mathrm{g} / \mathrm{m}^{3}\right)$. Table 1 summarizes the pollution values of each training session, the corresponding assigned $\mathrm{PM}_{10}$ level, and the number of athletes attending that session.

\section{Statistical analysis}

Due to non-normal distribution of urinary metal concentrations, non-parametric testing and reporting of data were used. Results are reported as median values and interquartile range (IQR; 25 th to 75 th quartile range). In detail, comparisons of paired data (e.g., before vs. after the training session) were evaluated by means of the Wilcoxon test, whereas significant differences among the three different $\mathrm{PM}_{10}$ levels were assessed by means of the Kruskal-Wallis test, followed by the Mann-Whitney $U$ test to detect statistical differences

Table $1 \mathrm{PM}_{10}$ values during the 10 training sessions, together with the assigned pollution level and the number of athletes participating to each of the trainings

\begin{tabular}{llll}
\hline $\begin{array}{l}\text { Training ses- } \\
\text { sion }\end{array}$ & $\mathrm{PM}_{10}\left(\mu \mathrm{g} / \mathrm{m}^{3}\right)$ & $\begin{array}{l}\text { Assigned pollu- } \\
\text { tion level }\end{array}$ & $\begin{array}{l}\text { Number of } \\
\text { participants }\end{array}$ \\
\hline 1 & 22.5 & 2 & 7 \\
2 & 50.7 & 3 & 8 \\
3 & 45.6 & 3 & 6 \\
4 & 23.5 & 2 & 4 \\
5 & 4.0 & 1 & 6 \\
6 & 36.2 & 2 & 6 \\
7 & 15.4 & 1 & 5 \\
8 & 33.8 & 2 & 6 \\
9 & 42.3 & 3 & 5 \\
10 & 4.2 & 1 & 6 \\
\hline
\end{tabular}

between specific subgroups. Correlation of continuous $\mathrm{PM}_{10}$ concentrations with urinary metal concentrations was assessed by Spearman's correlation coefficient $r_{\mathrm{s}}$. All the tests were two-tailed and a level of $p<0.05$ was considered statistically significant. For the statistical analysis, the SPSS software (Statistical Package for Social Science) was used.

A standardized average squared effect of 0.20 was detected based on a preliminary experimentation. This value yielded a power of 0.857 for 8 observations per cell in a two-way $(3 \times 2)$ analysis of variance. In the current paper, a minimum of 17 data are included in each cell, resulting in a power of 0.992 .

\section{Results}

Overall, 8 male athletes accepted to be volunteers of the study; their individual age and anthropometric characteristics are summarized in Table 2. Median age was 23 years, stature $182 \mathrm{~cm}$, pre-training body mass $80.3 \mathrm{~kg}$, and body mass index (BMI) $24.2 \mathrm{~kg} / \mathrm{m}^{2}$. For each athlete, median values of body mass before and after the training sessions, the percentage change in body mass (pre- minus post-session), and the volume of water drunk are reported in Table 2. Cumulatively, the percentage change of body mass had a median value of $0.30 \%$ (IQR $0.11-0.55 \%$ ) and never exceeded 3\% (Francescato et al. 2019) in all the athletes and in all the training sessions. Overall, the volume of water drunk had a median value of $200 \mathrm{~mL}$, never exceeding $800 \mathrm{~mL}$.

Median concentrations (and IQR range) of 15 metals/ metalloids in urine collected before and after the training sessions, as well as their median change (expressed in percentage) are summarized in Table 3. Cumulatively, the median urine concentration of each of 10 metals (As, $\mathrm{Cd}, \mathrm{Co}, \mathrm{Cu}, \mathrm{Mn}, \mathrm{Ni}, \mathrm{Pb}, \mathrm{Se}, \mathrm{Tl}$, and $\mathrm{Zn}$ ) was significantly increased on average by $46.2 \%$ after the training session

Table 2 Anthropometric characteristics of 8 non-professional American football player subjects. Median body mass (and IQR) before and after the training sessions, as well as its change (expressed in percentage), is reported for each athlete

\begin{tabular}{llllllll}
\hline Athlete & Age (years) & Stature $(\mathrm{cm})$ & $\begin{array}{l}\text { Body mass before } \\
(\mathrm{kg})\end{array}$ & BMI before $\left(\mathrm{kg} / \mathrm{m}^{2}\right)$ & Body mass after $(\mathrm{kg})$ & $\begin{array}{l}\text { Change in body } \\
\text { mass before-after } \\
(\%)\end{array}$ & $\begin{array}{l}\text { Water drunk }(\mathrm{mL}) \\
\text { b }\end{array}$ \\
\hline S1 & 23 & 182 & $80.3(79.8-80.7)$ & $24.2(24.1-24.3)$ & $80.2(79.7-80.3)$ & $0.12(0.12-0.53)$ & $150(25-237)$ \\
S2 & 29 & 180 & $96.3(95.5-96.7)$ & $29.7(29.5-29.8)$ & $96.3(95.2-96.5)$ & $0.05(-0.16-0.42)$ & $475(200-600)$ \\
S3 & 18 & 187 & $91.4(91.0-91.6)$ & $26.1(26.0-26.2)$ & $91.0(90.3-91.2)$ & $0.55(0.41-0.77)$ & $250(200-500)$ \\
S4 & 28 & 201 & $102.7(102.0-103.4)$ & $25.4(25.2-25.6)$ & $101.9(101.7-103.1)$ & $0.20(0.19-0.39)$ & $130(0-350)$ \\
S5 & 23 & 180 & $100.4(99.9-101.2)$ & $31.0(30.8-31.2)$ & $100.1(99.8-100.8)$ & $0.15(0.10-0.40)$ & $200(150-350)$ \\
S6 & 23 & 190 & $113.4(113.2-114.6)$ & $31.4(31.4-31.7)$ & $113.0(112.8-113.3)$ & $0.35(0.00-0.44)$ & $350(100-500)$ \\
S7 & 22 & 184 & $84.4(83.7-86.5)$ & $24.9(24.7-25.5)$ & $83.9(83.3-86.1)$ & $0.36(0.24-0.69)$ & $125(0-350)$ \\
S8 & 22 & 198 & $131.9(131.7-132.0)$ & $33.6(33.6-33.7)$ & $131.2(131.1-131.4)$ & $0.46(0.46-0.51)$ & $100(25-325)$ \\
\hline
\end{tabular}


Table 3 Median concentrations of metals in urine of 8 nonprofessional American football players before and after 10 training sessions. Statistical significance was assessed by the Wilcoxon test

\begin{tabular}{|c|c|c|c|c|}
\hline Metal & Pre-sessions & Post-sessions & $\%$ change & $p$-value \\
\hline $\mathrm{Al}(\mu \mathrm{g} / \mathrm{L})$ & $4.75(2.34-12.37)$ & $6.22(3.34-12.22)$ & $11.6(-16.8-82.9)$ & $p=0.063$ \\
\hline As $(\mu \mathrm{g} / \mathrm{L})$ & $9.76(4.54-24.61)$ & $\begin{array}{l}14.61 \\
(8.62-33.08)\end{array}$ & $43.1(-0.09-132.3)$ & $p<0.001$ \\
\hline $\mathrm{Be}(\mu \mathrm{g} / \mathrm{L})$ & $0.168(0.005-0.390)$ & $0.254(0.005-0.393)$ & $0.0(-35.1-97.6)$ & $p=0.228$ \\
\hline $\mathrm{Cd}(\mu \mathrm{g} / \mathrm{L})$ & $0.412(0.252-0.641)$ & $0.612(0.437-0.892)$ & $54.7(14.0-120.3)$ & $p<0.001$ \\
\hline Co $(\mu \mathrm{g} / \mathrm{L})$ & $0.490(0.216-0.614)$ & $0.589(0.273-0.783)$ & $25.1(-0.2-68.7)$ & $p=0.018$ \\
\hline $\mathrm{Cr}(\mu \mathrm{g} / \mathrm{L})$ & $67.3(45.9-98.8)$ & $63.9(42.2-85.4)$ & $-8.0(-30.7-43.0)$ & $p=0.207$ \\
\hline $\mathrm{Cu}(\mu \mathrm{g} / \mathrm{L})$ & 7.23 (4.89-9.11) & $12.62(10.37-16.42)$ & $71.0(31.4-151.7)$ & $p<0.001$ \\
\hline $\operatorname{Mn}(\mu \mathrm{g} / \mathrm{L})$ & $4.83(2.07-7.49)$ & $6.32(3.27-9.10)$ & $11.7(-6.0-57.1)$ & $p=0.019$ \\
\hline $\mathrm{Ni}(\mu \mathrm{g} / \mathrm{L})$ & $1.13(0.77-1.40)$ & $1.83(1.44-2.44)$ & $54.7(27.1-107.9)$ & $p<0.001$ \\
\hline $\mathrm{Pb}(\mu \mathrm{g} / \mathrm{L})$ & $1.39(0.86-2.95)$ & $2.35(0.96-4.21)$ & $27.6(-4.2-64.8)$ & $p=0.003$ \\
\hline $\mathrm{Se}(\mu \mathrm{g} / \mathrm{L})$ & $50.83(38.13-62.76)$ & $77.64(63.56-97.87)$ & $55.5(22.3-109.9)$ & $p<0.001$ \\
\hline $\mathrm{Tl}(\mu \mathrm{g} / \mathrm{L})$ & $0.200(0.144-0.343)$ & $0.250(0.163-0.373)$ & $20.7(-9.15-53.7)$ & $p=0.005$ \\
\hline $\mathrm{U}(\mu \mathrm{g} / \mathrm{L})$ & $0.352(0.191-0.714)$ & $\begin{array}{l}0.284 \\
(0.143-0.567)\end{array}$ & $\begin{array}{l}-2.2 \\
(-63.6-39.7)\end{array}$ & $p=0.248$ \\
\hline $\mathrm{V}(\mu \mathrm{g} / \mathrm{L})$ & $14.23(8.58-26.11)$ & $11.15(6.5-18.19)$ & $-25.7(-41.9-4.0)$ & $p=0.001$ \\
\hline $\mathrm{Zn}(\mu \mathrm{g} / \mathrm{L})$ & $224.7(91.4-342.9)$ & $443.3(291.3-645.3)$ & $97.6(33.7-280.4)$ & $p<0.001$ \\
\hline
\end{tabular}

Note. Statistically significant differences are highlighted in bold character
(Wilcoxon test; $p<0.05$ ); on the opposite, vanadium concentration decreased significantly by $27.5 \%$ (Wilcoxon test; $p<0.001)$; the concentration of the remaining 4 metals $(\mathrm{Al}, \mathrm{Be}, \mathrm{Cr}$, and $\mathrm{U})$ did not change.

We further analyzed the data according to air pollution by stratified low, medium, and high $\mathrm{PM}_{10}$ levels; 3 training sessions were included in the low $\mathrm{PM}_{10}$ level, 4 sessions in the medium $\mathrm{PM}_{10}$ level, and 3 in the high $\mathrm{PM}_{10}$ level.

The stratified $\mathrm{PM}_{10}$ levels affected significantly the urine concentrations of 5 metals $(\mathrm{Be}, \mathrm{Cd}, \mathrm{Cu}, \mathrm{Tl}$, and $\mathrm{V})$, as illustrated in Figs. 1 and 2. Specifically, the pre-session values of $\mathrm{Be}, \mathrm{Cd}, \mathrm{Cu}$, and $\mathrm{Tl}$ were significantly higher at high $\mathrm{PM}_{10}$ levels than the corresponding pre-session values at low or medium $\mathrm{PM}_{10}$ levels. The same trend was observed among the post-session values, where the high $\mathrm{PM}_{10}$ levels were significantly higher than the low or medium $\mathrm{PM}_{10}$ levels. At variance, $\mathrm{V}$ showed a peculiar trend, because the cumulative post-session concentrations were significantly lower than the cumulative pre-session ones. Notably, vanadium post-session values at high and medium $\mathrm{PM}_{10}$ levels were significantly lower than the post-session values at low $\mathrm{PM}_{10}$ levels.

A further analysis showed a statistically significant bivariate correlation between continuous $\mathrm{PM}_{10}$ concentrations and the urine concentrations of the pre-session values of $\mathrm{Be}\left(r_{\mathrm{s}}=0.436, p=0.001\right), \mathrm{Cd}\left(r_{\mathrm{s}}=0.293, p=\right.$ $0.026), \mathrm{Tl}\left(r_{\mathrm{s}}=0.316, p=0.015\right)$, and $\mathrm{V}\left(r_{\mathrm{s}}=-0.292\right.$, $p=0.025)$, as well as the post-session values of $\mathrm{Be}\left(r_{\mathrm{s}}=\right.$ $0.281, p=0.036)$ and $\mathrm{Tl}\left(r_{\mathrm{s}}=0.276, p=0.035\right)$. No other statistical significant correlation with continuous values of $\mathrm{PM}_{10}$ was found.
Figure 2 shows the urine concentrations of 4 metals $(\mathrm{Cu}$, $\mathrm{Ni}, \mathrm{Se}, \mathrm{Zn}$ ) that were significantly higher in the post-sessions compared to the pre-sessions collectively as well as for each stratified $\mathrm{PM}_{10}$ level ( $p<0.05$ for all the comparisons).

Figure 3 illustrates urine concentrations of the 4 metals (As, $\mathrm{Co}, \mathrm{Mn}$, and $\mathrm{Pb}$ ) for which a statistically significant increase was observed cumulatively in the overall posttraining measurements compared to the pre-training ones, whereas the data did not reach significant values in each of the three specific $\mathrm{PM}_{10}$ levels.

For $\mathrm{Al}$ and $\mathrm{Cr}$ only occasional significant differences were observed (Fig. 4); finally, no significant differences were detected for $\mathrm{U}$.

\section{Discussion}

Exposure of athletes to air pollution during sport activities may pose subjects to potential adverse health effects and/ or reduction of athletic performances. The dose of inhaled pollution is difficult to estimate because several factors may contribute including levels of pollutants, ventilation rate, physiological characteristics of each athlete, duration and intensity of exercise, hydration status, individual oxidative stress, and inflammation levels. Such evaluation by quantitative biomarkers, however, is considered critically important to estimate the health effects (Ali et al. 2019).

We found that 15 metals are measurable in the urine of athletes. For most metals, concentrations after exercise were increased, and for some metals, levels were modulated by air pollution. These findings suggest that, in general, inhaled air 

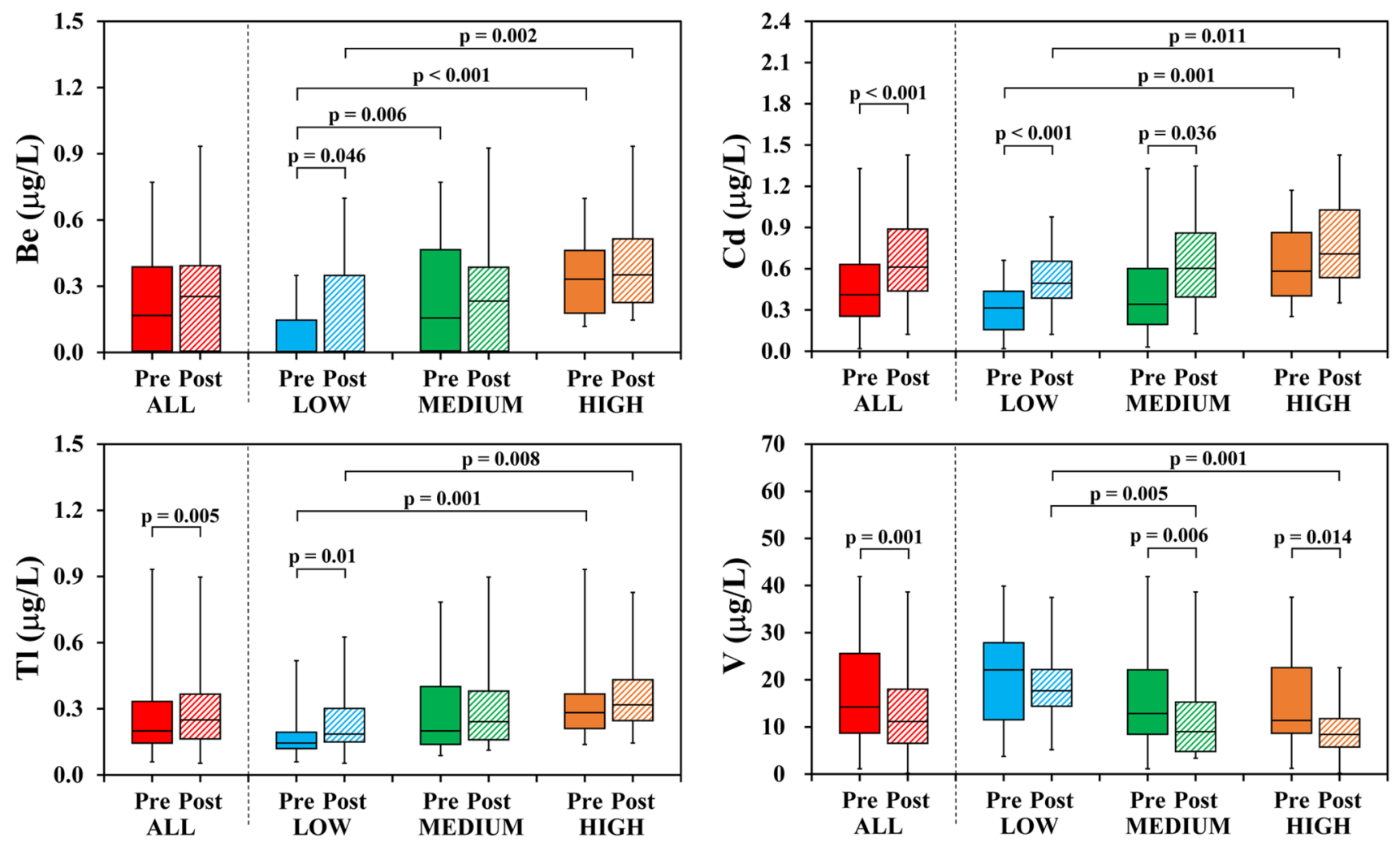

Fig. 1 Urine concentrations of 4 toxic metals (Be, Cd, Tl, V) before and after a 2-h training session in 8 non-professional American football players. Results are also illustrated according to 3 different levels of air pollution (low, medium, and high, respectively)

during the day affects urinary metals excretions (Men et al. 2020). Thus, in our opinion, determination of metals may constitute a non-invasive biomarker to inform about pollution exposure of athletes, and consequently, urinary metals could be potential indicators for estimation of health risks.

\section{Effects of the training sessions on the urinary metal concentrations}

The main finding of our research is that after 2-h of outdoor exercise, the majority of urinary metal $(10 / 15 ; 67 \%)$ concentrations were increased on an average of $46.2 \%$; specifically, the single metal increase was as follows: As $43.1 \%$, Cd 54.7\%, Co $25.1 \%$, Cu 71.0\%, Mn 11.7\%, Ni 54.7\%, Pb $27.6 \%$, Se $55.5 \%$, Tl 20.7\%, Zn 97.6\%. It has to be highlighted that the metals showing the greatest increase were $\mathrm{Zn}$ and $\mathrm{Cu}$, two metals which are frequently interrelated in physiological processes (Chan et al. 1998). An exception was vanadium, which decreased by $25.7 \%$ after exercise, implying specific excretion/body distribution mechanisms for this metal (Toro-Román et al. 2021). In our study, dehydration following exercise did not have a major impact. Indeed, the median change in body mass amounted to $0.30 \%$ (IQR $0.11-0.55 \%$ ) and never exceeded 3\%, which is considered the threshold of physiological significance (Francescato et al. 2019). Moreover, $\mathrm{Al}, \mathrm{Be}, \mathrm{Cr}$, and $\mathrm{U}$ urine concentrations were not changed after exercise, confirming the negligible changes due to hydration status.

Increased concentrations of metals following exercise have several potential implications.

The increase of metals in urine after the exercise may be due to several mechanisms including enhanced kidney excretion connected to physical activity and/or increased body absorption by inhalation due to higher ventilation rate, paralleled by increased excretion. Intriguingly, in COVID-19 patients, urinary metals have been positively correlated to increased serum pro-inflammatory cytokines, neutrophils, and white blood cells, but negatively correlated with lymphocytes (Zeng et al. 2021), a typical inflammatory profile observed also in athletes post-exercise (Giovanelli et al. 2020; Pedersen and Toft 2000).

It is worth noting that increased concentrations of urinary metals, particularly As and $\mathrm{Cd}$, could have direct effects on epithelial cells of the kidney and urinary system (Gonick 2002), potentially causing in the long term diseases such as chronic kidney disease (Chen et al. 2021) and even bladder cancer (Tsuji et al. 2021). Evidence suggests that the cytotoxic effect of metals causing diseases are mainly due to increased oxidative stress (Afridi et al. 2010; Buha et al. 2021; Liu et al. 2009; Vaziri 2002). 

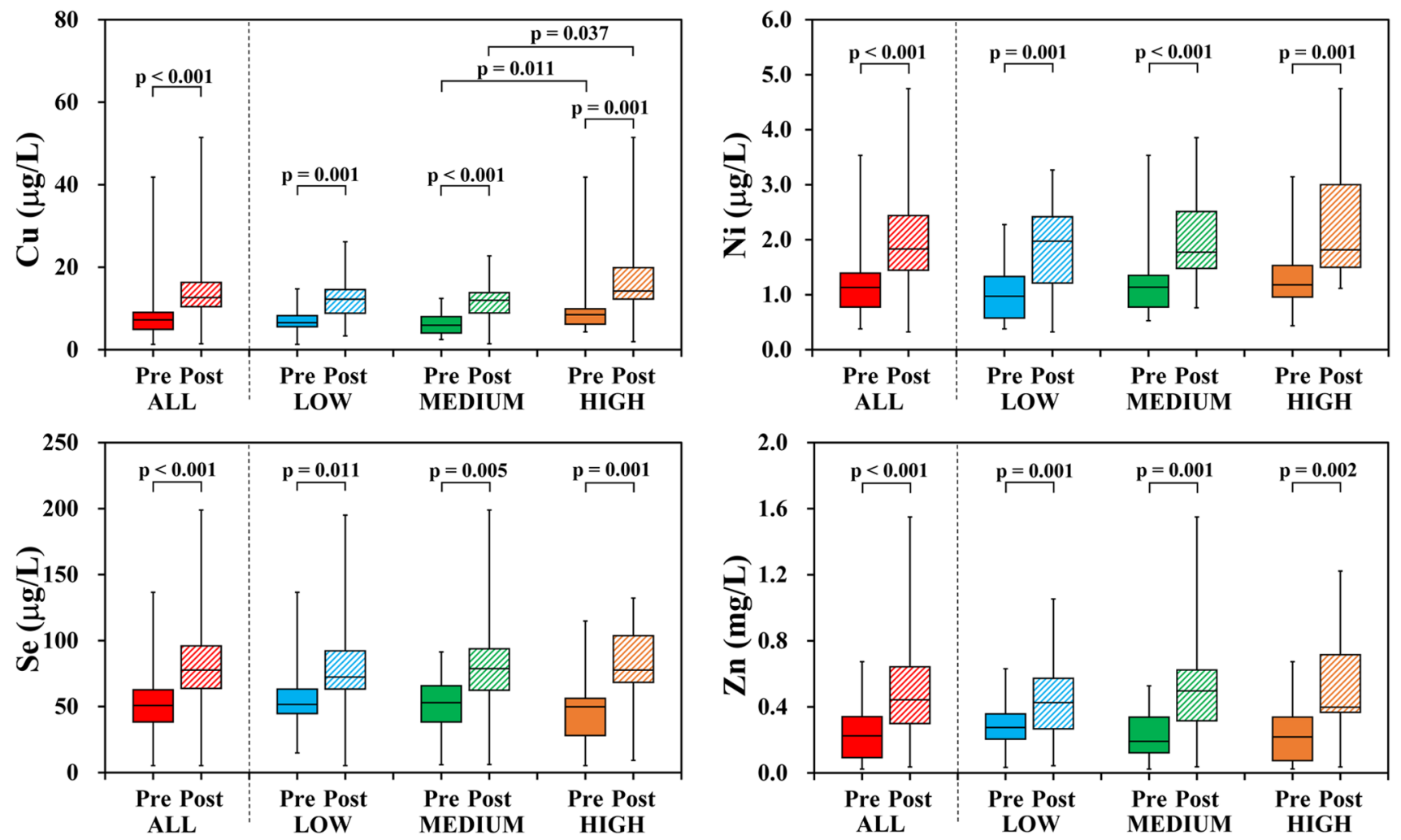

Fig. 2 Urine concentrations of 4 metals $(\mathrm{Cu}, \mathrm{Ni}, \mathrm{Se}, \mathrm{Zn})$ before and after a 2-h training session in 8 non-professional American football players, for which the cumulative and the three subdivided groups

Further studies are necessary to assess whether increases of urinary metals that we observed after exercise contribute to subclinical and/or clinical conditions frequently observed in athletes (Afridi et al. 2010; Francescato et al. 2020; Gonick 2002; Stang et al. 2018).

So far, a paucity of scientific attention was devoted to the changes in urinary metal concentrations induced by physical exercise.

Our results are in line with some previous studies (Anderson et al. 1984; Bartolomé et al. 2016; Granell 2014; Maynar et al. 2018a, b) showing a significant increase of urinary $\mathrm{Zn}$ concentrations after exercise compared to pre-exercise levels. Indeed, in our study, $\mathrm{Zn}$ showed the largest increase, being almost doubled after exercise. $\mathrm{Zn}$ together with other metals like Se and $\mathrm{Mn}$ is one of the essential elements usually measured to monitor nutritional status; however, also these metals are present in polluted air, and when their concentration is excessively high, being emitted by coal and wood combustions, industrial fossil powers, welding processes, steel mills, waste incinerators, traffic pollution, etc., they can indeed cause disease (Bauer et al. 2020; Chowdhury et al. 2018; Kieliszek 2021; Knoop et al. 2020; Montano et al. 2021).

according to $\mathrm{PM}_{10}$ were all higher after training. Results are also illustrated according to the 3 different levels of air pollution (low, medium, and high, respectively)

A 1.5-fold increase of urinary $\mathrm{Zn}$ was observed by Anderson et al. (1984) in nine male runners (23-46 years) running 6 miles near their maximal pace; however, at variance with our study, Anderson et al. (1984) found an increase of $\mathrm{Cr}$ and a not significant variation of $\mathrm{Cu}$. Our findings of increased urinary $\mathrm{Zn}$ and $\mathrm{Cu}$ were in line with the study by Granell (2014) performed on 22 subjects after aerobic endurance. Additionally, Maynar et al. (2018a, b) found a significant increase in urinary $\mathrm{Zn}$ in Spanish runners who ran until exhaustion, although these authors did not find an increase in urinary Se and Mo. The same group of authors did not find changes in urinary concentrations of Co and $\mathrm{Mn}$ after an acute exercise test performed to exhaustion by 21 Spanish national endurance (long and middle distances) athletes, whereas $\mathrm{Cu}$ concentrations were significantly lower (Muñoz et al. 2019).

Another study examined 7 urinary metals: $\mathrm{As}, \mathrm{Cu}, \mathrm{Li}$, $\mathrm{Mo}, \mathrm{Ni}, \mathrm{Se}$, and $\mathrm{Zn}$ before and after a paddle competition (Bartolomé et al. 2016). Urinary excretion of $\mathrm{Cu}, \mathrm{Ni}$, and $\mathrm{Zn}$ increased significantly similar to the present study, whereas no changes in As, Mo, and Se were observed. Interestingly, Li decreased significantly after the paddle effort in the study by Bartolomé et al. (2016), a behavior which appears similar 

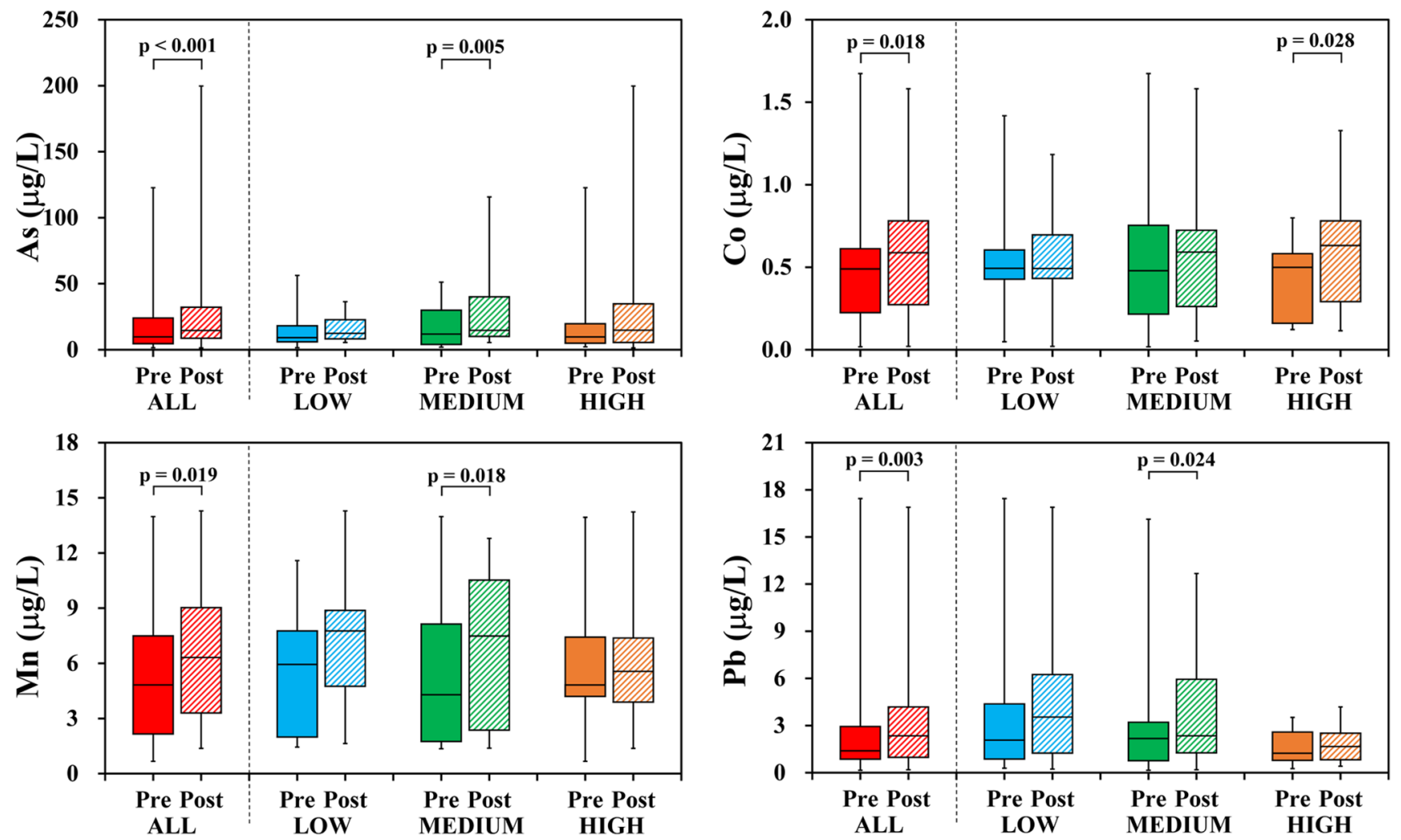

Fig. 3. Urine concentrations of 4 metals ( $\mathrm{As}, \mathrm{Co}, \mathrm{Mn}, \mathrm{Pb}$ ) before and after a 2-h training session in 8 non-professional American football players, for which the cumulative values were higher after training, but not all the three subdivided groups according to $\mathrm{PM}_{10}$ reached significance

to the decrease of $\mathrm{V}$ concentration that we observed in the current study.

The upregulation of the renin-angiotensin-aldosterone axis typically provoked by physical exercise (Francescato et al. 2019) could be responsible at least in part for the consistently observed increase in urinary $\mathrm{Zn}$ concentration (Rosenblum et al. 2020).

Chromium (Cr) is a heavy metal particularly investigated because of its health toxic effects that, like those of several other metals, are mediated by oxidative stress (Buha et al. 2021). In our study, $\mathrm{Cr}$ did not increase after exercise. $\mathrm{Cr}$ is widespread in the environment mainly in two oxidative states, $\mathrm{Cr}(\mathrm{III})$ and $\mathrm{Cr}(\mathrm{VI})$; thus, several pathways are involved in its metabolism. $\mathrm{Cr}(\mathrm{VI})$ is known to be toxic and included in the first group of carcinogens for humans (IARC), inducing numerous pathological changes in the respiratory, urinary, reproductive, and digestive systems (Anderson et al. 1984; Buha et al. 2021). Conversely, the much less toxic $\mathrm{Cr}(\mathrm{III})$ has no well-defined physiological role, although it has pharmacological applications, in particular in diabetes (Sijko et al. 2021).

Out of the 15 metals studied, uranium (U) showed a particular behavior, as it was unaffected by physical exercise and by air pollution. Uranium is widespread on Earth. Chronic exposure occurs through multiple routes, including ingestion via food or drinking water, but also through inhalation of resuspended particulate matter (Harmon et al. 2017), although very rarely, uranium is measured as a component of $\mathrm{PM}_{10}$ due to its constancy, unless in proximity of uranium mines (Harmon et al. 2017).

The variable results obtained in various urinary metals biomonitoring studies on athletes could be derived in part from the physiological mechanisms of transport, storing, and detoxification of the toxic metals, which include the action of ferritin and transferrin. It is known that ferritin exerts protective effects by capturing toxic metals like $\mathrm{Al}, \mathrm{As}, \mathrm{Be}, \mathrm{Cd}, \mathrm{Pb}$, and V (Betteridge 2000; Lindenschmidt et al. 1986; Polanams et al. 2005). Transferrin and other molecules like albumin, metallothionein, and $\beta 2$-microglubulin may modulate toxic metals by binding their ions, thus affecting kidney excretion (Fels et al. 2019). Furthermore, specific individual conditions, modulated by iron status and inflammatory conditions, may have a major impact on body metals metabolism (Pedersen and Toft 2000; Suh et al. 2016; Zeng et al. 2021).

\section{Effects of air pollution $\left(\mathrm{PM}_{10}\right)$ level on the urinary metals concentrations}

No study so far examined the effects of exposure to varying air pollution levels during exercise on urinary concentrations 

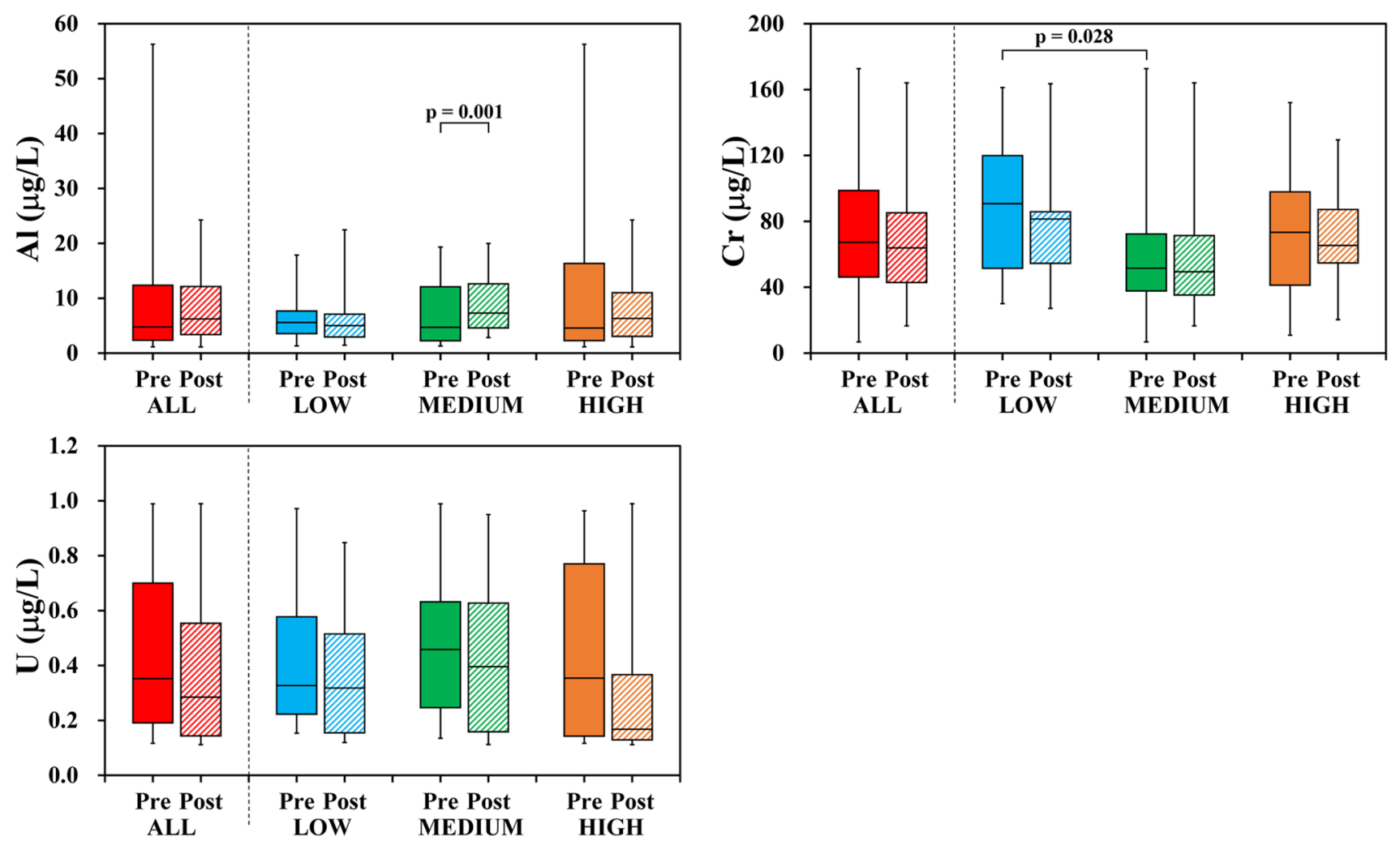

Fig. 4 Urine concentrations of 3 metals (Al, Cr, U) before and after a 2-h training session in 8 non-professional American football players, for which only occasional differences were observed

of metals. Our study investigated the association of 15 urinary metal concentrations with outdoor air pollution before and after 10 different days of 2-h training, in which the level of air pollution was almost equally distributed in low (3 sessions), medium (4 sessions), and high $\mathrm{PM}_{10}$ level (3 sessions). Five metals showed statistically significant differences according to the air pollution. Concentrations of $\mathrm{Be}$, $\mathrm{Cd}, \mathrm{Cu}$, and $\mathrm{Tl}$ were increased with increasing air pollution; on the opposite, V concentration was decreased. Importantly, we found that urinary $\mathrm{Be}$ and $\mathrm{Tl}$ were positively correlated to air pollution before and after exercise raising the evidence that inhaled polluting metals affect urinary excretion also independently of physical activity. Our findings of modulation of some metal levels in the pre-session suggest that pollution over the whole day may affect urinary metal levels. Such a phenomenon might become the topic of further studies.

Metals that in our study were modulated by $\mathrm{PM}_{10}$ have specific features as described below.

Beryllium In our study, urinary Be increased according to increased stratified and continuous $\mathrm{PM}_{10}$. Be is a human and animal carcinogen for lungs of class 1 (IARC); exposure tends to occur via inhalation of Be fumes or dust (Mayer and Hamzeh 2015). The organic forms of Be are rapidly excreted, but the insoluble inorganic particle can remain in the body for many years (Sizar and Talati 2021). Exposure to $\mathrm{Be}$ in some subjects causes sensitization (likely due to genetic predisposition) and conjunctivitis (Balmes et al. 2014). Beryllium-exposed individuals and their physicians may be unaware of their exposure (Balmes et al. 2014; Schaller 2012). Ambient air levels of Be are normally very low $\left(<0.03 \mathrm{ng} / \mathrm{m}^{3}\right)$ (Sizar and Talati 2021) unless in proximity of Be processing industries (Perrino et al. 2020).

Cadmium We observed that $\mathrm{Cd}$ had higher concentrations at high compared to low stratified PM $_{10}$ levels both pre- and post-exercise, respectively. Furthermore, pre-session continuous concentrations of $\mathrm{Cd}$ were positively correlated to continuous $\mathrm{PM}_{10}$ values. $\mathrm{Cd}$ is a heavy metal with highly toxic effects, released from natural sources, like volcanic eruptions and forest fires, and from several anthropogenic sources, for instance coal powers, gasoline combustion, corrosion of steel (Afridi et al. 2010; Satarug et al. 2010). Cd's main toxicity included the kidneys, prostate, and bone, being carcinogenic to class 1 (IARC). Similar to $\mathrm{As}, \mathrm{Cu}$, and $\mathrm{Pb}$, the level of exposure to $\mathrm{Cd}$ affects toxicity and also, moderate environmental exposure might increase the risk of CVD (Chowdhury et al. 2018; Deering et al. 2018). 
Exposure to inhaled $\mathrm{Cd}$ might be associated with asthma (Mattila et al. 2021), although smoking confounds this association because of the content of $\mathrm{Cd}$ in cigarettes (Yang et al. 2019). Interestingly, the urinary concentration of $\mathrm{Cd}$ has been associated with asthma (Huang et al. 2016). Some evidence indicates that depressed iron levels increase adsorption of other metals like cadmium and that increased blood cadmium concentrations are observed in subjects with Iron deficit anemia (Suh et al. 2016).

Copper Our data showed that $\mathrm{Cu}$ had higher concentrations at high compared to medium stratified $\mathrm{PM}_{10}$ levels both pre- and post-exercise, respectively. $\mathrm{Cu}$ is an essential micronutrient that is involved in several enzymatic functions, but that can be harmful when in excess (Uriu-Adams and Keen 2005). Therefore, $\mathrm{Cu}$ is under careful homeostatic controls due to the pathologic consequences of $\mathrm{Cu}$ dyshomeostasis (Gromadzka et al. 2020). $\mathrm{Cu}$ is involved in a multitude of physiological pathways; the two main ones are its function as cofactor in $\mathrm{Cu}$ and $\mathrm{Zn}$ superoxide dismutase, which regulates oxidative stress and the cytochrome $\mathrm{C}$ oxidase that is a crucial enzyme in oxidative phosphorylation. Thus, $\mathrm{Cu}$ has a pivotal role in the cellular energy production. Excess of $\mathrm{Cu}$ has been implicated in several pathologies particularly neurodegenerative diseases (Gromadzka et al. 2020) and cardiovascular events (Chowdhury et al. 2018). In our study, $\mathrm{Cu}$ urinary concentration increased after physical exercise and with high pollution raising the question whether these two conditions are associated with reduced $\mathrm{Cu}$ body stores.

Thallium In our study $\mathrm{Tl}$, similar to $\mathrm{Cd}$, had higher concentrations at high compared to low stratified $\mathrm{PM}_{10}$ levels both pre- and post-exercise, respectively. Additionally, Tl concentrations, similarly to $\mathrm{Be}$, were positively correlated to continuous $\mathrm{PM}_{10}$ both pre- and post-exercise. $\mathrm{Tl}$ is one of the most toxic heavy metals, being in particular highly neurotoxic even at low doses (Campanella et al. 2019). The primary route of poisoning is through ingestion, although respiratory absorption has also been reported (Liu and Liao 2021). Thallium ionic size and charge are very similar to potassium ion, so that it can substitute potassium for example in Na-K ATPases. It is conceivable that the increase of thallium post-exercise could parallel the increased excretion of $\mathrm{K}^{+}$known to occur in athletes (Francescato et al. 2019). Moreover, it has been demonstrated that the concentration of thallium, as well as that of other toxic metals, is positively correlated to inflammation (Zeng et al. 2021), an occurrence typical of physical exercise effort (Giovanelli et al. 2020). It is to note that in our study, no participant had urinary thallium concentration exceeding the normal upper limit of 0.89 $\mu \mathrm{g} / \mathrm{L}$ (Zeng et al. 2021).
Vanadium We found that post-exercise concentrations of $\mathrm{V}$ were lower at medium and high stratified $\mathrm{PM}_{10}$ levels compared to low $\mathrm{PM}_{10}$, respectively. Furthermore, pre-session continuous concentrations of $\mathrm{V}$ were negatively correlated to continuous $\mathrm{PM}_{10}$ values. $\mathrm{V}$ is a transition metal widely distributed in the Earth's crust and is a major contaminant in fossil fuels including coal and diesel combustion oil (Aydin et al. 2012; Barceloux 1999). Respirable vanadium present in $\mathrm{PM}_{10}$ has been associated with pulmonary and vascular toxicity through inflammatory reactions (Zychowski et al. 2018). Vanadium also adversely affects male reproductive functions (Chandra et al. 2010). Increased generation of reactive oxygen species and oxidative stress play a predominant role in vanadium-induced cytotoxicity. Indeed, oxidative stress has been reported to contribute to vanadium-induced pulmonary inflammation, neurotoxicity, and carcinogenicrelated effects (Zwolak 2014). In the human body, vanadium can exist mainly in the form of vanadate negative ions $\left(\mathrm{VO}_{3}{ }^{-4}\right)$, whose structure is similar to phosphate, or vanadyl cations $\left(\mathrm{VO}^{+2}\right)$. Metabolic detoxification of vanadium possibly involves reduction of vanadate to vanadyl by cellular reductants (including reduced glutathione, ascorbic acid, NADH, as well as pyruvic acid) (Zwolak 2020). A potent detoxification mechanism is also the storage of vanadium in bones (Zwolak 2020). In the bloodstream, transferrin, as well as other serum proteins and other molecular ligands such as lactate, is involved in the transport of vanadium. Final excretion of absorbed vanadium occurs through urine, likely as vanadyl ion (Rehder 2015). In our study, vanadium behaves in a unique way, being less excreted at high pollution levels. One possible hypothesis is that in more polluted conditions, the pool of antioxidant molecules is reduced and thus does not allow the conversion to vanadyl ion, necessary for vanadium excretion. Interestingly, a recent study showed that vanadium has higher serum concentrations in athletes compared to non-athlete controls (Toro-Román et al. 2021). Such a finding fits with a reduced excretion of vanadium provoked by physical exercise. Although these hypotheses are intriguing, many other pathways could be involved due to the complexity of vanadium metabolism. Finally, the decrease of vanadium after exercise mimics that of lithium observed by other authors (Bartolomé et al. 2016). The effects of exercise, in particular the increase of lactate, and air pollution on vanadium excretion is a challenging issue that should be further studied.

\section{Strengths and limitations}

Strengths of the current study are (a) the elevated number of metals measured in urine samples; (b) the homogeneous group of athletes, which were all male American Football players at the same level of agonistic performance and having rather similar physiological characteristics like age, 
BMI, etc.; (c) the ethnic homogeneity (all Caucasian subjects) and living in the same Italian region Friuli-Venezia Giulia at not more than a 30-km distance from the location of the sports field where all the experimental sessions and urine sample collections were performed; thus, presumably, participants were exposed similarly to air pollution also outside sport activities; (d) the days of training sessions were all performed in winter-start of spring, i.e., in rather similar weather conditions.

Limitations include (a) exercise was mainly of aerobic type performed for 2-h in late afternoon, effects on urine metals for athletes engaged in different types of sport, or shorter as well as longer physical activity time, and at lower or higher air pollution levels remain to be determined; (b) we determined short-term effects immediately after exercise, not long-term effects; (c) different ethnicity and grade of athleticism may potentially modify air inhalation and metal excretion rates; (d) the design of our study did not include measurements of metals in body fluids different from urine, like blood or sweat; (e) among pollutants present in polluted air, we examined metals neglecting other toxic molecules like benzene, toluene, xilenes, etc. Finally, sex effects on metal metabolism and urinary excretions should be investigated (Francescato et al. 2019), as well as excretion after longer time periods after the end of the exercise.

\section{Conclusions}

Human biomonitoring is increasingly used as a tool for quantifying human exposure to chemicals in order to inform about public health, and for risk assessment and management decisions also in view of precision medicine approaches.

We first demonstrated that 15 metals are detectable in the urine of athletes and that most metals' concentrations (10/15 metals) are modulated by 2 -h outdoor exercises and, for 5 metals, by air pollution. Our results suggest that the urine of athletes can be used as a non-invasive tool to assess exposure to toxic molecules potentially inhalable in polluted air. Among the examined metals, urinary $\mathrm{Be}, \mathrm{Cd}, \mathrm{Cu}, \mathrm{Tl}$, and $\mathrm{V}$ determinations seem more promising as inhaled pollution biomarkers.

Objective quantifiable pollution markers determination in athletes can suggest appropriate training schedules and sport location choices overall reducing exposure. Importantly, we found that urinary concentrations of two highly toxic metals $\mathrm{Be}$ and $\mathrm{Tl}$ are positively correlated to $\mathrm{PM}_{10}$ both before and after training; thus, objective biochemical evaluation of exposure can enhance awareness of pollution effects. Our findings can hopefully induce athletes, training coaches, and athletic organizers to avoid air polluted urban areas in proximity of highly metal-polluting industries (Gonzalez Ortiz and De Brito Beirao Guerreiro 2020), like steelworks, waste incinerators, and fossil energy powers as well as high traffic roads.

Acknowledgements We thank Patrizia Nacci, Luca Bazzichetto, Luigi Di Giacomo and Silvia Lolini for technical support, Department of Medicine (University of Udine).

Availability of data and materials The datasets used and/or analyzed during the current study are available from the corresponding author on reasonable request.

Authors' contributions SC conceptualization and design of the study, investigation, writing, supervision and review editing, resources; MT methodology, investigation and data acquisition; FC project administration, methodology, supervision; MPF design of the study, data curation and analysis, writing the draft, review editing. All authors read and approved the final manuscript.

Funding The study was performed with unconditional support from the University of Udine (institutional grant to Prof. S. Cauci; year 2017-2019).

\section{Declarations}

Ethics approval and consent to participate Written informed consent was obtained from each participant before enrolment and no compensation or incentive was paid to the participants for this study. The study was approved by the Institutional Ethical Committee of the Department of Medicine (University of Udine) and was conducted according to the Declaration of Helsinki.

Consent for publication Not applicable.

Competing interests The authors declare that they have no competing interests.

\section{References}

Afridi HI, Kazi TG et al (2010) Evaluation of cadmium, lead, nickel and zinc status in biological samples of smokers and nonsmokers hypertensive patients. J Human Hypertension 24:34-43. https:// doi.org/10.1038/jhh.2009.39

Ali MU, Liu G, Yousaf B, Ullah H, Abbas Q, Munir MAM (2019) A systematic review on global pollution status of particulate matter-associated potential toxic elements and health perspectives in urban environment. Environ Geochem Health 41:1131-1162. https://doi.org/10.1007/s10653-018-0203-Z

An R, Shen J, Ying B, Tainio M, Andersen ZJ, de Nazelle A (2019) Impact of ambient air pollution on physical activity and sedentary behavior in China: a systematic review. Environ Res 176:108545. https://doi.org/10.1016/j.envres.2019.108545

An R, Yu H (2018) Impact of ambient fine particulate matter air pollution on health behaviors: a longitudinal study of university students in Beijing, China. Public Health 159:107-115. https://doi. org/10.1016/j.puhe.2018.02.007

Anderson RA, Bryden NA, Polansky MM, Deuster PA (1995) Acute exercise effects on urinary losses and serum concentrations of copper and zinc of moderately trained and untrained men consuming a controlled diet. Analyst 120:867-870. https://doi.org/ $10.1039 /$ an9952000867 
Anderson RA, Polansky MM, Bryden NA (1984) Acute effects on chromium, copper, zinc, and selected clinical variables in urine and serum of male runners. Biol Trace Element Res 6:327-336. https://doi.org/10.1007/bf02989240

Aydin F, Saydut A, Gunduz B, Aydin I, Hamamci C (2012) Chemical speciation of vanadium in coal bottom ash. CLEAN - Soil. Air, Water 40:444-448. https://doi.org/10.1002/clen.201100195

Balmes JR, Abraham JL et al (2014) An official American Thoracic Society statement: diagnosis and management of beryllium sensitivity and chronic beryllium disease. Am J Respir Crit Care Med 190:e34-e59. https://doi.org/10.1164/rccm.201409-1722ST

Barceloux DG (1999) Vanadium. J Toxicol Clin Toxicol 37:265-278. https://doi.org/10.1081/clt-100102425

Bartolomé I, Córdoba L, Crespo C, Grijota F, Maynar M, Muñoz D (2016) Effects of a paddle match on the urinary excretion of trace minerals in high-level players. Sci Sports 31:e131-e137. https:// doi.org/10.1016/j.scispo.2015.12.004

Bauer JA, Devick KL et al (2020) Associations of a metal mixture measured in multiple biomarkers with IQ: evidence from Italian adolescents living near Ferroalloy Industry. Environ Health Perspect 128:97002. https://doi.org/10.1289/ehp6803

Bergamo P, Volpe MG et al (2016) Human semen as an early, sensitive biomarker of highly polluted living environment in healthy men: a pilot biomonitoring study on trace elements in blood and semen and their relationship with sperm quality and RedOx status. Reprod Toxicol 66:1-9. https://doi.org/10.1016/j.reprotox.2016. 07.018

Betteridge DJ (2000) What is oxidative stress? Metab - Clin Exp 49:38. https://doi.org/10.1016/S0026-0495(00)80077-3

Bigazzi AY, Figliozzi MA (2014) Review of urban bicyclists' intake and uptake of traffic-related air pollution. Transport Rev 34:221245. https://doi.org/10.1080/01441647.2014.897772

Brook RD, Newby DE, Rajagopalan S (2017) Air pollution and cardiometabolic disease: an update and call for clinical trials. Am J Hypertension 31:1-10. https://doi.org/10.1093/ajh/hpx109

Buha A, Baralic K et al (2021) The role of toxic metals and metalloids in Nrf2 signaling. Antioxidants (Basel) 10:630. https://doi.org/ 10.3390/antiox 10050630

Campanella B, Colombaioni L et al (2019) Toxicity of thallium at low doses: a review. Int J Environ Res Public Health 16. https://doi. org/10.3390/ijerph16234732

Chan S, Gerson B, Subramaniam S (1998) The role of copper, molybdenum, selenium, and zinc in nutrition and health. Clin Lab Med 18:673-685. https://doi.org/10.1016/s0272-2712(18)30143-4

Chandra AK, Ghosh R, Chatterjee A, Sarkar M (2010) Protection against vanadium-induced testicular toxicity by testosterone propionate in rats. Toxicol Mech Methods 20:306-315. https://doi. org/10.3109/15376516.2010.485623

Chen X, Chen X et al (2021) The association between estimated glomerular filtration rate and cadmium exposure: an 8-year follow-up study. Int J Hygiene Environ Health 235:113774. https://doi.org/ 10.1016/j.ijheh.2021.113774

Chowdhury R, Ramond A et al (2018) Environmental toxic metal contaminants and risk of cardiovascular disease: systematic review and meta-analysis. Bmj 362:k3310. https://doi.org/10.1136/bmj. $\mathrm{k} 3310$

de Nazelle A, Bode O, Orjuela JP (2017) Comparison of air pollution exposures in active vs. passive travel modes in European cities: a quantitative review. Environ Int 99:151-160. https://doi.org/10. 1016/j.envint.2016.12.023

Deering KE, Callan AC et al (2018) Low-level cadmium exposure and cardiovascular outcomes in elderly Australian women: a cohort study. Int J Hygiene Environ Health 221:347-354. https://doi.org/ 10.1016/j.ijheh.2017.12.007

Dons E, Laeremans M et al (2017) Wearable sensors for personal monitoring and estimation of inhaled traffic-related air pollution: evaluation of methods. Environ Sci Technol 51:1859-1867. https://doi.org/10.1021/acs.est.6b05782

Fels J, Scharner B, et al. (2019) Cadmium complexed with $\beta 2$-microglubulin, albumin and lipocalin-2 rather than metallothionein cause megalin:cubilin dependent toxicity of the renal proximal tubule. Int J Mol Sci 20. https://doi.org/10.3390/ijms2 0102379

Forastiere F, Agabiti N (2013) Assessing the link between air pollution and heart failure. Lancet 382:1008-1010. https://doi.org/10.1016/ S0140-6736(13)61167-8

Francescato MP, Canciani M, Cettolo V (2020) Interchangeability between two breath-by-breath $\mathrm{O}(2)$ uptake calculation algorithms in asthmatic and healthy volunteers. Eur J Appl Physiol 120:14171428. https://doi.org/10.1007/s00421-020-04374-w

Francescato MP, Venuto I, Stella AB, Stel G, Mallardi F, Cauci S (2019) Sex differences in hydration status among adolescent elite soccer players. J Human Sport Exercise 14:265-280. https://doi. org/10.14198/jhse.2019.142.02

Giovanelli N, Lazzer S, Cauci S (2020) Muscle damage and inflammatory status biomarkers after a 3-stage trail running race. J Sports Med Phys Fitness 60:1486-1492. https://doi.org/10.23736/s00224707.20.10997-6

Gonick HC (2002) Lead, renal disease and hypertension. Am J Kidney Dis 40:202-204. https://doi.org/10.1053/ajkd.2002.34681

Gonzalez Ortiz A, De Brito Beirao Guerreiro C (2020) Air quality in Europe - 2020 report. EEA Report No 9/2020. https://doi.org/10. $2800 / 786656$

Granell J (2014) Zinc and copper changes in serum and urine after aerobic endurance and muscular strength exercise. J Sports Med Phys Fitness 54:232-237

Gromadzka G, Tarnacka B, Flaga A, Adamczyk A (2020) Copper dyshomeostasis in neurodegenerative diseases-therapeutic implications. Int J Mol Sci 21. https://doi.org/10.3390/ijms21239259

Harmon ME, Lewis J et al (2017) Residential proximity to abandoned uranium mines and serum inflammatory potential in chronically exposed Navajo communities. J Expo Sci Environ Epidemiol 27:365-371. https://doi.org/10.1038/jes.2016.79

Huang X, Xie J et al (2016) Association between Concentrations of metals in urine and adult asthma: a case-control study in Wuhan, China. PLoS One 11:e0155818. https://doi.org/10.1371/journal. pone. 0155818

IARC (International Agency for Research on Cancer) List of Classifications. Agents classified by the IARC Monographs, Volumes 1-129. IARC Monographs on the Identification of Carcinogenic Hazards to Humans

Kieliszek M (2021) Chapter Eleven - selenium. Advances in Food and Nutrition Research. N. A. M. Eskin Academic Press 96:417-429

Knoop A, Planitz P, Wüst B, Thevis M (2020) Analysis of cobalt for human sports drug testing purposes using ICP- and LC-ICP-MS. Drug Test Anal 12:1666-1672. https://doi.org/10.1002/dta.2962

Koh HY, Kim TH et al (2019) Serum heavy metal levels are associated with asthma, allergic rhinitis, atopic dermatitis, allergic multimorbidity, and airflow obstruction. J Allergy Clin Immunol Pract 7:2912-2915.e2912. https://doi.org/10.1016/j.jaip.2019.05.015

Lindenschmidt RC, Sendelbach LE, Witschi HP, Price DJ, Fleming J, Joshi JG (1986) Ferritin and in vivo beryllium toxicity. Toxicol Appl Pharmacol 82:344-350. https://doi.org/10.1016/0041$008 x(86) 90211-5$

Liu H, Liao G (2021) Long-term misdiagnosis and neurologic outcomes of thallium poisoning: a case report and literature review. Brain Behav 11:e02032. https://doi.org/10.1002/brb3.2032

Liu J, Qu W, Kadiiska MB (2009) Role of oxidative stress in cadmium toxicity and carcinogenesis. Toxicol Appl Pharmacol 238:209214. hhttps://doi.org/10.1016/j.taap.2009.01.029

Llerena F, Maynar M, Barrientos G, Palomo R, Robles MC, Caballero MJ (2012) Comparison of urine toxic metals concentrations 
in athletes and in sedentary subjects living in the same area of Extremadura (Spain). Eur J Appl Physiol 112:3027-3031. https://doi.org/10.1007/s00421-011-2276-6

Lucchini RG, Guazzetti S et al (2019) Neurocognitive impact of metal exposure and social stressors among schoolchildren in Taranto, Italy. Environ Health 18:67. https://doi.org/10.1186/ s12940-019-0505-3

Mattila T, Santonen T, et al. (2021) Scoping Review-The association between asthma and environmental chemicals. Int J Environ Res Public Health 18. https://doi.org/10.3390/ijerph18031323

Mayer A, Hamzeh N (2015) Beryllium and other metal-induced lung disease. Curr Opin Pulm Med 21:178-184. https://doi.org/10. 1097/mcp.0000000000000140

Maynar M, Llerena F et al (2018a) Influence of an exercise until exhaustion in serum and urinary concentrations of toxic minerals among professional athletes, a preliminary approach. J Trace Elements Med Biol 50:312-319. https://doi.org/10.1016/j. jtemb.2018.07.022

Maynar M, Muñoz D et al (2018b) Influence of an acute exercise until exhaustion on serum and urinary concentrations of molybdenum, selenium, and zinc in athletes. Biol Trace Element Res 186:361-369. https://doi.org/10.1007/s12011-018-1327-9

Men Y, Li L et al (2020) Evaluation of heavy metals and metabolites in the urine of patients with breast cancer. Oncol Lett 19:13311337. https://doi.org/10.3892/ol.2019.11206

Menke A, Muntner P, Silbergeld EK, Platz EA, Guallar E (2009) Cadmium levels in urine and mortality among U.S. adults. Environ Health Perspectives 117:190-196. https://doi.org/10.1289/ ehp. 11236

Mills NL, Donaldson K et al (2009) Adverse cardiovascular effects of air pollution. Nature Clin Practice Cardiovasc Med 6:36-44. https://doi.org/10.1038/ncpcardio1399

Mistaro A, Felluga A et al (2018) Chemical characterization of atmospheric particulate matter in Friuli Venezia Giulia (NE Italy) by exploratory data analysis with multisite and multivariate approach. Environ Sci Pollution Res 25:28808-28828. https://doi.org/10.1007/s11356-018-1883-8

Montano L, Ceretti E et al (2021) Effects of a lifestyle change intervention on semen quality in healthy young men living in highly polluted areas in Italy: The FASt Randomized Controlled Trial. Eur Urol Focus. https://doi.org/10.1016/j.euf.2021.01.017

Moon JY, Eom SY et al (2021) Effects of exposure to lead and cadmium on health of inhabitants of abandoned metal mine area in Korea. Arch Environ Contam Toxicol 80:490-498. https://doi. org/10.1007/s00244-021-00813-7

Muñoz D, Grijota FJ, Bartolomé I, Siquier-Coll J, Toro-Román V, Maynar M (2020) Serum and urinary concentrations of arsenic, beryllium, cadmium and lead after an aerobic training period of six months in aerobic athletes and sedentary people. J Int Soc Sports Nutrition 17:43. https://doi.org/10.1186/ s12970-020-00372-7

Muñoz D, Maynar M et al (2019) Effect of an acute exercise until exhaustion on the serum and urinary concentrations of cobalt, copper, and manganese among well-trained athletes. Biol Trace Element Res 189:387-394. https://doi.org/10.1007/ s12011-018-1500-1

Nawrot TS, Perez L, Künzli N, Munters E, Nemery B (2011) Public health importance of triggers of myocardial infarction: a comparative risk assessment. Lancet 377:732-740. https://doi.org/ 10.1016/s0140-6736(10)62296-9

Newby DE, Mannucci PM et al (2015) Expert position paper on air pollution and cardiovascular disease. Eur Heart J 36:83-93. https://doi.org/10.1093/eurheartj/ehu458

Pedersen BK, Toft AD (2000) Effects of exercise on lymphocytes and cytokines. Br J Sports Med 34:246-251. https://doi.org/10. 1136/bjsm.34.4.246
Perrino C, Catrambone M, Canepari S (2020) Chemical composition of PM10 in 16 urban, industrial and background sites in Italy. Atmosphere 11:479. https://doi.org/10.3390/atmos11050479

Polanams J, Ray AD, Watt RK (2005) Nanophase iron phosphate, iron arsenate, iron vanadate, and iron molybdate minerals synthesized within the protein cage of ferritin. Inorg Chem 44:3203-3209. https://doi.org/10.1021/ic048819r

Qin F, Yang Y et al (2019) Exercise and air pollutants exposure: a systematic review and meta-analysis. Life Sciences 218:153-164. https://doi.org/10.1016/j.lfs.2018.12.036

Rehder D (2015) The role of vanadium in biology. Metallomics 7:730 742. https://doi.org/10.1039/c4mt00304g

Renzetti S, Cagna G et al (2021) The effects of the exposure to neurotoxic elements on Italian schoolchildren behavior. Scientific Reports 11:9898. https://doi.org/10.1038/s41598-021-88969-z

Rosenblum H, Wessler JD, Gupta A, Maurer MS, Bikdeli B (2020) Zinc deficiency and heart failure: a systematic review of the current literature. J Card Fail 26:180-189. https://doi.org/10.1016/j. cardfail.2020.01.005

Satarug S, Garrett SH, Sens MA, Sens DA (2010) Cadmium, environmental exposure, and health outcomes. Environ Health Perspect 118:182-190. https://doi.org/10.1289/ehp.0901234

Satarug S, Moore MR (2004) Adverse health effects of chronic exposure to low-level cadmium in foodstuffs and cigarette smoke. Environ Health Perspect 112:1099-1103. https://doi.org/10.1289/ ehp. 6751

Schaller KH (2012) Beryllium and its inorganic compounds [BAT Value Documentation, 2005]. The MAK-Collection for Occupational Health and Safety:152-158. https://doi.org/10.1002/35276 00418.bb744041e0004

Sijko M, Janasik B, Wasowicz W, Kozlowska L (2021) Can the effects of chromium compounds exposure be modulated by vitamins and microelements? Int J Occup Med Environ Health. https://doi.org/ 10.13075/ijomeh.1896.01706

Sizar O, Talati R (2021) Berylliosis. [Updated 2020 Jun 30]. StatPearls [Internet]. StatPearls Publishing

Smith L, Panter J, Ogilvie D (2019) Characteristics of the environment and physical activity in midlife: findings from UK Biobank. Preventive Med 118:150-158. https://doi.org/10.1016/j.ypmed. 2018.10.024

Stang J, Sikkeland LIB, Tufvesson E, Holm AM, Stensrud T, Carlsen KH (2018) The role of airway inflammation and bronchial hyperresponsiveness in athlete's asthma. Med Sci Sports Exercise 50:659-666. https://doi.org/10.1249/MSS.0000000000001478

Suh YJ, Lee JE et al (2016) Prevalence and Relationships of Iron Deficiency Anemia with Blood Cadmium and Vitamin D Levels in Korean Women. J Korean Med Sci 31:25-32. https://doi.org/10. 3346/jkms.2016.31.1.25

Tainio M, Jovanovic Andersen Z et al (2021) Air pollution, physical activity and health: a mapping review of the evidence. Environ Int 147:105954. https://doi.org/10.1016/j.envint.2020.105954

Toro-Román V, Bartolomé I et al (2021) Serum vanadium concentrations in different sports modalities. Journal of Trace Elements in Medicine and Biology 68:126808. https://doi.org/10.1016/j.jtemb. 2021.126808

Tsuji JS, Lennox KP, Watson HN, Chang ET (2021) Essential concepts for interpreting the dose-response of low-level arsenic exposure in epidemiological studies. Toxicology 457:152801. https://doi.org/ 10.1016/j.tox.2021.152801

Uriu-Adams JY, Keen CL (2005) Copper, oxidative stress, and human health. Mol Aspects Med 26:268-298. https://doi.org/10.1016/j. mam.2005.07.015

Vaziri ND (2002) Pathogenesis of lead-induced hypertension: role of oxidative stress. J Hypertens Suppl 20:S15-S20

WHO (2021). WHO Global Conference on Air Pollution and Health. 30 October - 1 November. 2021 
Wilschefski SC, Baxter MR (2019) Inductively Coupled Plasma Mass Spectrometry: Introduction to Analytical Aspects. Clin Biochem Rev 40:115-133. https://doi.org/10.33176/aacb-19-00024

Yang G, Sun T et al (2019) Serum Cadmium and Lead, Current Wheeze, and Lung Function in a Nationwide Study of Adults in the United States. J Allergy Clin Immunol Pract 7:2653-2660. e2653. https://doi.org/10.1016/j.jaip.2019.05.029

Yao X, Steven XX et al (2021) Stratification of population in NHANES 2009-2014 based on exposure pattern of lead, cadmium, mercury, and arsenic and their association with cardiovascular, renal and respiratory outcomes. Environment International 149:106410. https://doi.org/10.1016/j.envint.2021.106410

Zeng HL, Zhang B, Wang X, Yang Q, Cheng L (2021) Urinary trace elements in association with disease severity and outcome in patients with COVID-19. Environmental Research 194:110670. https://doi.org/10.1016/j.envres.2020.110670
Zwolak I (2014) Vanadium carcinogenic, immunotoxic and neurotoxic effects: a review of in vitro studies. Toxicol Mech Methods 24:112. https://doi.org/10.3109/15376516.2013.843110

Zwolak I (2020) Protective Effects of Dietary Antioxidants against Vanadium-Induced Toxicity: A Review. Oxid Med Cell Longev 2020:1490316. https://doi.org/10.1155/2020/1490316

Zychowski KE, Kodali V et al (2018) Respirable Uranyl-VanadateContaining Particulate Matter Derived From a Legacy Uranium Mine Site Exhibits Potentiated Cardiopulmonary Toxicity. Toxicol Sci 164:101-114. https://doi.org/10.1093/toxsci/kfy064

Publisher's note Springer Nature remains neutral with regard to jurisdictional claims in published maps and institutional affiliations. 